\title{
Healthcare workers' role in keeping MMR vaccination uptake high in Europe: a review of evidence
}

B Simone $^{1,2}$, P Carrillo-Santisteve ${ }^{1}$, P L Lopalco (pierluigi.lopalco@ecdc.europa.eu) ${ }^{1}$

1. European Centre for Disease Prevention and Control (ECDC), Stockholm, Sweden

2. Institute of Hygiene, Universitá Cattolica del Sacro Cuore, Rome, Italy

Simone B, Carrillo-Santisteve P, Lopalco PL. Healthcare workers' role in keeping MMR vaccination uptake high in Europe: a review of evidence. Euro Surveill. 2012;17(26):pii=20206. Available online: http://www.eurosurveillance.org/ViewArticle.aspx?Articleld=20206

Measles is a highly contagious and potentially fatal disease. Europe is far from the $95 \%$ coverage rates necessary for elimination of the disease, although a safe and cost-effective vaccine is available. We reviewed the literature on studies carried out in European countries from January 1991 to September 2011 on knowledge, attitudes and practices of health professionals towards measles vaccination and on how health professionals have an impact on parental vaccination choices. Both quantitative and qualitative studies were considered: a total of 28 eligible articles were retrieved. Healthcare workers are considered by parents as a primary and trustworthy source of information on childhood vaccination. Gaps in knowledge and poor communication from healthcare workers are detrimental to high immunisation rates. Correct and transparent information for parents plays a key role in parental decisions on whether to have their children vaccinated. Healthcare workers' knowledge of and positive attitudes towards measles-mumps-rubella (MMR) vaccination are crucial to meeting the measles elimination goal. An effort should be made to overcome potential communication barriers and to strengthen vaccine education among healthcare professionals.

\section{Introduction}

Measles is a highly contagious disease and a leading cause of death among children below five years-old worldwide, although a safe and cost-effective vaccine is available [1]. Although measles usually runs a simple course, serious complications can occur: the most common in industrialised countries are otitis media (in $7-9 \%$ of cases), pneumonia (1-6\%), diarrhoea ( $8 \%$ ), post-infectious encephalitis (1 per $1,000-2,000$ cases), subacute sclerosing panencephalitis (SSPE) (1 per 100,000 cases) and death (1-3 per 1,000 cases) [2]. Women who are infected during pregnancy are at greater risk of miscarriage and premature delivery [2]. Individuals at high risk of developing complications are children under 5 years of age, adults and individuals with chronic diseases and impaired immunity $[1,3]$.
The most common way of administration of the measles vaccine is in combination with the mumps and rubella vaccines (the trivalent mumps-measles-rubella (MMR) vaccine), which is a combination of the three live attenuated viruses. Since its introduction in the 1970s, an estimated 500 million doses of MMR vaccine have been administered in over 60 countries worldwide [4]. Some countries have adopted a quadrivalent vaccine (MMRV), which also includes varicella [5].

Before vaccines were available, measles affected most people by adolescence; today, thanks to routine vaccination programmes, the disease is not seen as frequently in Europe. Eliminating measles and congenital rubella syndrome - that is, reducing to zero the incidence of infection [6] - is a goal that all European countries are committed to meet by $2015[6,7]$. In order to eliminate measles, it is necessary to reach and maintain measles vaccination coverage at 95\% $[1,7]$. Currently, however, the vaccination coverage is still far from this level: in fact, a drop in vaccine coverage rates to suboptimal levels has been reported in Europe in recent years $[8,9]$.

In the first eight months of 2011 alone, more than 29,000 cases of measles were reported in Europe. About one third of them required hospitalisation and in the first six months of the year, measles was responsible for eight deaths and 24 cases of acute encephalitis [9].

Currently there is no standard European policy of administration of the MMR vaccine: of 30 European countries, vaccines are administered at the paediatrician's office in 7 , in healthcare centres in 12, and in multiple locations in 11 [10, and data from European Centre for Disease Prevention and Control (ECDC) experts for Malta and Romania]. There are also considerable discrepancies in the administration schedules of the MMR vaccine among European Union (EU) countries: although the first dose is always recommended by the age of 18 months in all countries, age at the second dose of MMR vaccine varies widely, from 12 
TABLE 1

System of vaccine delivery and age at first and second measles-mumps-rubella vaccine dose as recommended by national programmes, by EU/EFTA country

\begin{tabular}{|c|c|c|c|c|}
\hline \multirow{2}{*}{ Country } & \multirow{2}{*}{ System } & \multicolumn{3}{|c|}{ Age } \\
\hline & & First dose & Second dose & Catch-up vaccination \\
\hline Austria & Combined & $12-24 \mathrm{~m}$ & $\ll 24 \mathrm{~m}$ & $7-9$ y, 9-17 y \\
\hline Belgium & Combined & $12-13 \mathrm{~m}$ & $10-13 y$ & $5-7 y, 14-16 y$ \\
\hline Bulgaria & GP/FD-based & $13 \mathrm{~m}$ & $12 \mathrm{y}$ & - \\
\hline Cyprus & Paediatrician-based & $12-15 \mathrm{~m}$ & $4-6 y$ & $11-12$ y \\
\hline Czech Republic & Paediatrician-based & $15 \mathrm{~m}$ & $21-25 \mathrm{~m}$ & - \\
\hline Denmark & GP/FD-based & $15 \mathrm{~m}$ & $12 \mathrm{y}$ & - \\
\hline Estonia & GP/FD-based & $12 \mathrm{~m}$ & $13 \mathrm{y}$ & - \\
\hline Finland & GP/FD-based & $14-18 \mathrm{~m}$ & $6 y$ & - \\
\hline France & Combined & $12-15 \mathrm{~m}$ & $25 \mathrm{~m}$ & $<6 \mathrm{y}$ \\
\hline Germany & Combined & $11-14 \mathrm{~m}$ & $15-23 \mathrm{~m}$ & - \\
\hline Greece & Paediatrician-based & $12-15 \mathrm{~m}$ & $4-6 y$ & - \\
\hline Hungary & Combined & $15 \mathrm{~m}$ & $11 \mathrm{y}$ & - \\
\hline Iceland & Combined & $18 \mathrm{~m}$ & $12 \mathrm{y}$ & - \\
\hline Ireland & GP/FD-based & $12-15 \mathrm{~m}$ & $4-5 y$ & $11-12$ y \\
\hline Italy & Combined & $12-15 \mathrm{~m}$ & $11-15 \mathrm{y}$ & - \\
\hline Latvia & GP/FD-based & $15 \mathrm{~m}$ & $7 \mathrm{y}$ & $12 \mathrm{y}$ \\
\hline Lithuania & Combined & $15-16 \mathrm{~m}$ & $6-7 y$ & $12 \mathrm{y}$ \\
\hline Luxembourg & Combined & $15-18 \mathrm{~m}$ & $5-6 y$ & - \\
\hline Malta & Paediatrician-based $^{a}$ & $13 \mathrm{~m}$ & $3 y$ & - \\
\hline Netherlands & GP/FD-based & $14 \mathrm{~m}$ & $9 \mathrm{y}$ & - \\
\hline Norway & GP/FD-based & $15 \mathrm{~m}$ & $12-13 y$ & - \\
\hline Poland & GP/FD-based & $6-7 \mathrm{~m}$ & $10 \mathrm{y}$ & $11-12 y$ \\
\hline Portugal & Combined & $15 \mathrm{~m}$ & $5-6 y$ & - \\
\hline Romania & GP/FD-based ${ }^{\mathrm{a}}$ & $12-15 \mathrm{~m}$ & $6-7 y$ & - \\
\hline Slovakia & Paediatrician-based & $14 \mathrm{~m}$ & $10 \mathrm{y}$ & - \\
\hline Slovenia & Paediatrician-based & $12-24 \mathrm{~m}$ & $5-6 y$ & - \\
\hline Spain & Paediatrician-based & $12-15 \mathrm{~m}$ & $3-6 y$ & - \\
\hline Sweden & GP/FD-based & $18 \mathrm{~m}$ & $12 \mathrm{y}$ & - \\
\hline Switzerland & Combined & $12 \mathrm{~m}^{\mathrm{a}}$ & $15-24 \mathrm{~m}^{\mathrm{a}}$ & - \\
\hline United Kingdom & GP/FD-based & $13 \mathrm{~m}$ & $40 \mathrm{~m}$ & - \\
\hline
\end{tabular}

Combined: both general practitioners/family doctors and paediatricians; EFTA: European Free Trade Association; EU: European Union; GP/FD: general practitioner/family doctor; m: months; y: years.

a Data from European Centre for Disease Prevention and Control (ECDC) experts.

Source: unless otherwise indicated, data adapted from the EUVACnet vaccination schedules [5], Van Esso et al. [10] and VENICE report [11]).

months to 15 years [11]. Some EU countries have also implemented catch-up vaccination programmes, which are very heterogeneous in terms of age of those eligible (Table 1).

In spite of the solid evidence base on the efficacy and safety of measles vaccination [2], attitudes and practices of healthcare workers in Europe appear at times erratic: the misconception that measles is not a serious threat to health persists, not only among the parents of young children, but also among healthcare providers [12]. In this sense, there is complacency towards measles that is not present with regard to other vaccine-preventable diseases such as polio, tetanus or bacterial meningitis, which are generally perceived as extremely serious threats to health [12]. Memory of diseases and their severity fades quickly: because of routine vaccination programmes, there are generations of doctors, nurses and parents who have never seen measles or complications caused by measles.

Especially after a British study linked the MMR vaccine to increased incidence of autism, Crohn disease and other disorders [13], coverage in some European countries dropped, resulting in measles outbreaks and consistent burden of disease and costs [12]. Although the vaccine-autism controversy was dismissed and the article retracted by the journal editors [14] and 
although all possible associations were repeatedly disproven [15-17], the misconception that the vaccine risks outweigh those related to acquiring natural measles immunity is still widespread among parents [16]. Practices such as measles parties are said to have made a comeback in recent years [18] and anti-vaccination groups are common and active, especially on the Internet. Furthermore, the ever-increasing recourse to alternative practices such as homeopathy has been associated with higher rates of rejection of vaccines $[19,20]$.

The objectives of our study were: (i) to review the literature produced in European countries on the knowledge, attitudes and practices of health professionals towards measles vaccination and (ii) to assess how health professionals have an impact on parental vaccination choices.

\section{Methods}

\section{Eligibility criteria}

\section{Study types}

Studies reporting the knowledge, attitudes and practices of healthcare workers (general practitioners, paediatricians, other doctors, nurses, midwives) towards measles or MMR vaccination, as well as those reporting the influence of healthcare workers' attitudes on parental vaccination choices for their children, were eligible for inclusion. Both quantitative (surveys) and qualitative studies (focus groups) and reviews of literature focusing on one or more EU/European Economic Area (EEA) countries were searched.

\section{Types of data}

The types of data collected were: prevalence and characteristics (demographics, profession, practice/ training in alternative medicine) of healthcare workers partially or entirely unfavourable to measles/MMR vaccination; common reasons for advising against vaccination; prevalence of unvaccinated children attributable to healthcare workers' knowledge, attitudes and practices; opinions of parents towards healthcare workers as a reliable source of information on MMR vaccine efficacy and safety; and common reasons for parental distrust towards healthcare workers.

\section{Data sources and search methods}

for identification of studies

We searched MEDLINE and Embase. All records with the following terms were retrieved: attitude to health; health personnel OR parents; vaccine OR immunisation; Europe OR EU OR [list of EU and EEA/European

\section{FIGURE}

Search strategy for review of studies reporting knowledge, attitudes and practices of healthcare workers towards measles or MMR vaccination and those reporting the influence of healthcare workers' attitudes on parental vaccination choices

519 potentially relevant articles identified and screened for retrieval in MEDLINE (463 results), Embase (further 56 results) and Cochrane Library (zero results) databases

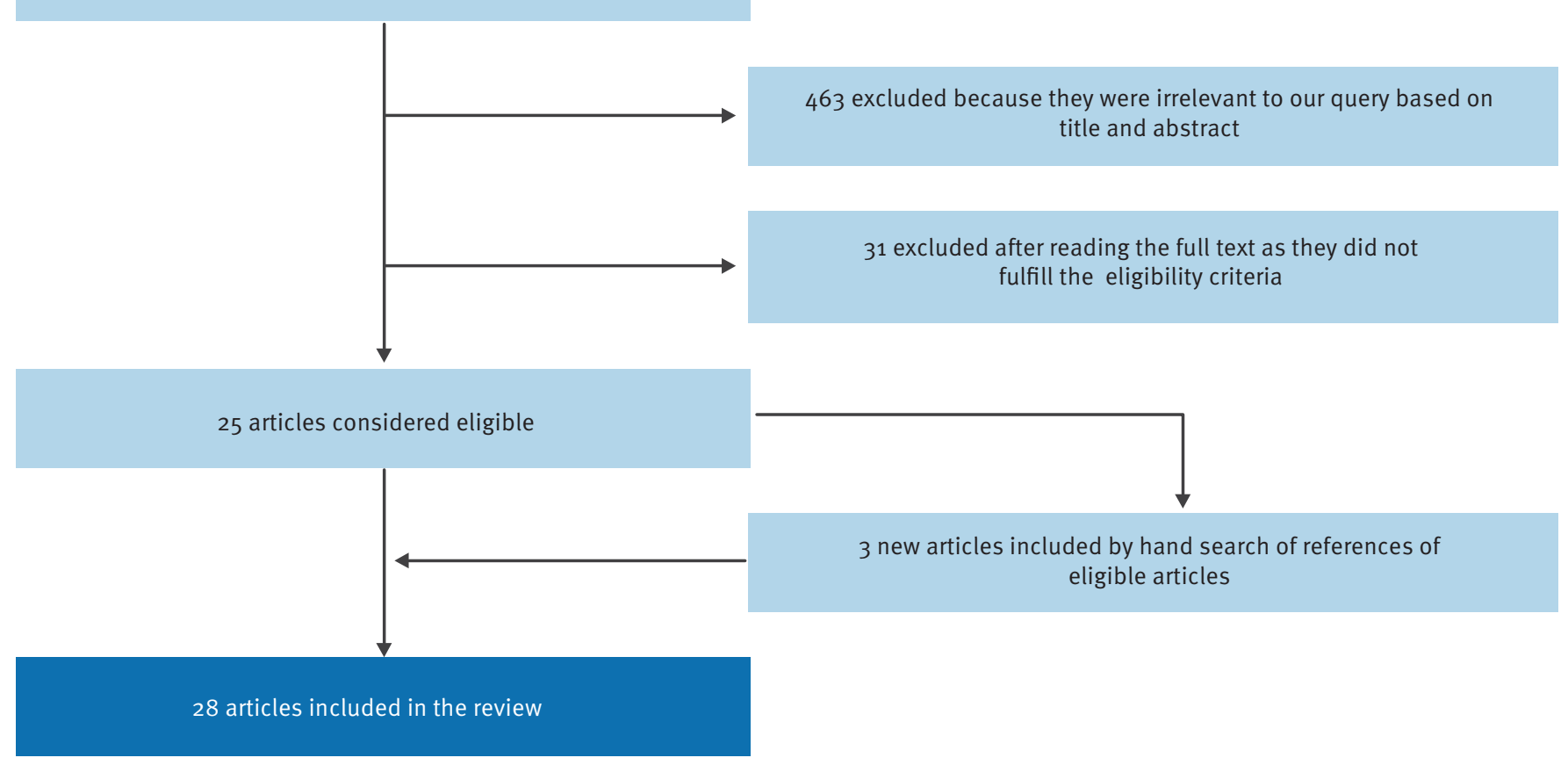


TABLE 2

Relevant studies reporting knowledge, attitudes and practices of healthcare workers towards measles or MMR vaccination and those reporting the influence of healthcare workers' attitudes on parental vaccination choices $(n=28)$

\begin{tabular}{|c|c|c|c|}
\hline Study & Setting & Type of study & Study population \\
\hline Anastasi et al. [21] & $\begin{array}{c}\text { Nine randomly selected boards of physicians, } \\
\text { Italy }\end{array}$ & Questionnaire survey & 500 randomly selected paediatricians \\
\hline Angelillo et al. [22] & $\begin{array}{c}\text { Randomly selected kindergartens in Cassino } \\
\text { (Frosinone) and Crotone, Italy }\end{array}$ & Questionnaire survey & 841 mothers of infants \\
\hline $\begin{array}{l}\text { Commité français } \\
\text { d'éducation pour la } \\
\text { santé [23] }\end{array}$ & France & Questionnaire survey & 2,000 general practitioners \\
\hline Hak et al. [24] & $\begin{array}{c}\text { Day-care centres associated with a large } \\
\text { organisation, the Netherlands }\end{array}$ & $\begin{array}{l}\text { Focus group and } \\
\text { questionnaire survey }\end{array}$ & $\begin{array}{l}283 \text { parents of } 3 \text {-month to } 5 \text {-year-old } \\
\text { children }\end{array}$ \\
\hline Petrovic et al. [25] & North Wales Health Authority Area, UK & Questionnaire survey & $\begin{array}{l}148 \text { health visitors, } 239 \text { practice nurses } \\
\text { and } 206 \text { general practitioners }\end{array}$ \\
\hline Smith et al. [26] & $\begin{array}{l}\text { Salford and Trafford Health Authority Area, } \\
\text { UK }\end{array}$ & Questionnaire survey & $\begin{array}{l}136 \text { general practitioners, } 78 \text { practice } \\
\text { nurses, } 40 \text { health visitors }\end{array}$ \\
\hline Cotter et al. [27] & Counties Cork and Kerry, Ireland & Focus group & $\begin{array}{l}47 \text { parents, } 23 \text { public health nurses, } 14 \\
\text { midwives, } 12 \text { practice nurses }\end{array}$ \\
\hline Rotily et al. [28] & 12 counties, France & Interview survey & 7,382 parents of 3 year-old children \\
\hline Theeten et al. [29] & $\begin{array}{l}125 \text { randomly selected clusters in } 107 \\
\text { municipalities, Flanders, Belgium }\end{array}$ & Interview survey & $\begin{array}{c}\text { Parents of } 1,354 \text { children aged } 18 \text { to } 24 \\
\text { months }\end{array}$ \\
\hline $\begin{array}{l}\text { Posfay-Barbe et al. } \\
\text { [30] }\end{array}$ & Switzerland & Questionnaire survey & $\begin{array}{l}\text { 2,070 physicians subscribers } \\
\text { to Infovac.net }\end{array}$ \\
\hline Trier [31] & $\begin{array}{c}97 \text { general practices in the county of } \\
\text { Vestsjellænd, Denmark }\end{array}$ & Questionnaire survey & 171 general practitioners \\
\hline Ernst $[32,33]$ & Exeter, UK & Questionnaire survey & 45 homeopaths \\
\hline Schmidt et al. [34] & UK & Questionnaire survey & $\begin{array}{l}104 \text { homeopaths and } 22 \text { chiropractors } \\
\text { registered on three websites }\end{array}$ \\
\hline Lehrke et al. [35] & Germany & Questionnaire survey & $\begin{array}{l}219 \text { medically qualified homoeopathic and } \\
281 \text { non-homoeopathic physicians }\end{array}$ \\
\hline McMurray et al. [36] & Five general practices in the Leeds area, UK & $\begin{array}{c}\text { Interview survey } \\
\text { (qualitative) }\end{array}$ & $\begin{array}{l}69 \text { parents of children aged between } 4 \\
\text { and } 5 \text { years; } 12 \text { healthcare workers }\end{array}$ \\
\hline Ramsay et al. [37] & UK & $\begin{array}{c}\text { Cross-sectional interview } \\
\text { surveys }\end{array}$ & 1,016 mothers of children aged $\leq 3$ years \\
\hline Pareek et al. [38] & Birmingham, UK & Questionnaire survey & $\begin{array}{l}300 \text { mothers of children approaching a } \\
\text { routine MMR vaccination }\end{array}$ \\
\hline Coniglio et al. [39] & $\begin{array}{l}8 \text { randomly selected day-care centres in } \\
\text { Catania, Sicily, Italy }\end{array}$ & Questionnaire survey & Parents of 1,500 children aged $3-5$ years \\
\hline Impicciatore et al. [40] & 6 geographically dispersed centres in Italy & Questionnaire survey & $\begin{array}{l}1,035 \text { mothers of children } \\
6 \text { years-old or younger }\end{array}$ \\
\hline Heininger [41] & Germany & Questionnaire survey & 6,025 participants \\
\hline Dannetun et al. [42] & County of Östergötland, Sweden & Interview survey & $\begin{array}{l}203 \text { parents of children who had no date } \\
\text { registered for MMR vaccination } \\
\text { at a child health centre }\end{array}$ \\
\hline Stefanoff et al. [43] & England, Norway, Poland, Spain, Sweden & $\begin{array}{l}\text { Questionnaire and } \\
\text { interview surveys }\end{array}$ & $\begin{array}{c}\text { 6,611 parents of children aged } 0-2 \text { years } \\
\text { (England, Norway, Poland, Sweden) and } \\
0-3 \text { years (Spain) }\end{array}$ \\
\hline Swennen et al. [44] & Belgium & Interview survey & $\begin{array}{l}\text { Parents of } 1,110 \text { children from Flanders } \\
\text { and } 1,088 \text { from Wallonia } \\
\end{array}$ \\
\hline Smith et al. [45] & UK & Interview survey & 1,016 mothers of children aged $\leq 3$ years \\
\hline Brown et al. [46] & $\begin{array}{l}\text { Papers published in English between } \\
1987 \text { and } 2008\end{array}$ & Review & 31 studies ( 23 from Europe) \\
\hline Hilton et al. [47] & Central Scotland, UK & Focus group & 72 parents \\
\hline Casiday et al. [48] & $\begin{array}{l}\text { A primary care trust in } \\
\text { north-east England, UK }\end{array}$ & Questionnaire survey & $\begin{array}{c}\text { Parents of } 996 \text { children born from } \\
1 \text { Oct } 2000 \text { to } 30 \text { Sep } 2002\end{array}$ \\
\hline $\begin{array}{l}\text { Ciofi degli Atti et al. } \\
\text { [49] }\end{array}$ & Italy & Interview survey & Parents of 4,602 children aged 2 years \\
\hline
\end{tabular}

MMR: measles-mumps-rubella; UK: United Kingdom. 
Free Trade Association (EFTA) countries]. The Cochrane Library was also consulted. The search covered articles published from 1 January 1991 to 27 September 2011, the date of the search. No language restriction was applied in the search. Two researchers (PCS and BS) reviewed the records independently, then discussed and agreed on the eligibility of each study. All references of eligible articles were hand searched and evaluated.

\section{Data extraction and analyses}

The following information was extracted for each study: references, country/countries involved, setting and characteristics of the healthcare workers interviewed, including details of their professions, and summary of the relevant data.

\section{Results}

The MEDLINE search yielded 463 results and a further 56 results were obtained through Embase. No systematic review of measles/MMR was found in the search of the Cochrane Library. Of the 519 overall articles retrieved, 463 were discarded as the title and abstract were not relevant and 31 after reading the full text as they did not meet the eligibility criteria. A further three articles were retrieved through hand search of references from the eligible articles. A total of 28 articles overall were included, as shown in the Figure and Table 2.

Knowledge, attitudes and practices

of healthcare workers towards

measles/MMR vaccination

A 2009 survey conducted among 156 Italian paediatricians [21] reported that only $88 \%$ knew that measles vaccination was recommended in the country, and only $35 \%$ knew the vaccination calendar. As for perceptions of the utility of recommended vaccinations (including MMR), paediatricians were asked to assign a score on a scale from 1 to 10: only $10 \%$ of those sampled resulted very favourable (scores of 9 or 10), although this percentage was significantly higher among those who administered recommended vaccinations for infants (odds ratio (OR):3.3; 95\% confidence interval (Cl): 1.19.9). Only a quarter of respondents administered the recommended vaccinations (which include measles) (26\%), whereas among paediatricians who did not normally administer vaccines, $81 \%$ still advised parents to have their children immunised for recommended vaccinations. A total of $83 \%$ of the paediatricians sampled routinely provided information about recommended vaccinations to their patients, whereas a lower percentage ( $78 \%$ ) informed them about benefits and risks.

An article published in 1999 in the Bulletin of the World Health Organization [22] reported that around $10 \%$ of 841 mothers of kindergarten children sampled from two Italian towns declined MMR vaccination because they were advised against it by healthcare professionals before deciding.
A French survey from 2001 from the French Committee for Health Education (Commité français d'éducation pour la santé) [23] categorised the attitudes of 2000 general practitioners towards MMR vaccination into those who were: (i) very favourable, i.e. those who vaccinated systematically following the vaccination calendar (41\%); (ii) favourable, i.e. those who vaccinated depending on the situation and did not follow the vaccination calendar systematically (56\%); and (iii) unfavourable, i.e. those who disregarded the vaccination calendar (3\%). Overall, $6 \%$ of those sampled were very or rather unfavourable to MMR vaccination. Those who were unfavourable were mostly practitioners who practiced homeopathy and/or alternative medicine and who worked with higher social/educated classes. The vaccination practices of practitioners who were favourable to the vaccination were also likely to improve after further training on vaccination.

A survey performed in the Netherlands in 2005 [24], among 283 parents of children attending day-care centres, showed that a negative attitude towards future vaccinations was significantly more common among healthcare workers (OR: 4.2;95\% Cl: 1.4-12.6) and highly educated parents (OR: 3.3; 95\% Cl: 1.3-8.6) than among other parents.

Following the MMR-autism controversy, several studies were carried out on practitioners' attitudes towards MMR vaccination in the United Kingdom (UK) and Ireland. In north Wales, Petrovik et al. [25] found in 2001 that knowledge and practice among 593 healthcare professionals regarding the second MMR dose varied widely: $48 \%$ of healthcare professionals had reservations about the policy of giving the second MMR dose and 3\% disagreed with it.

From a UK survey from Smith et al. [26], 40\% of the 136 responding physicians were unsure of the need for the second dose and around 10\% thought it unnecessary.

In Ireland, a survey in 2001 among 86 general practitioners, nurses and parents [27] showed a negative impact on vaccination uptake due to health professionals' ambivalence about vaccinations, inability or unwillingness to answer parents' questions or lack of empathy with parents concerned about the alleged side effects of the vaccines.

A French telephone survey published in 2001 [28], among 7,382 parents, showed that the coverage was significantly higher among children attended by a paediatrician compared with children not attended by a paediatrician ( $90.9 \%$ vs $85.4 \%$, p $<0.001$ ).

A survey conducted in Flanders, Belgium, in 2004 [29] found that having completed the schedule for the MMR vaccine depended on the vaccinating physician: children mainly vaccinated by a general practitioner were less likely to be completely vaccinated (adjusted OR: $0.3 ; 95 \% \mathrm{Cl}: 0.1-0.7)$ than children mainly vaccinated 
by a paediatrician (reference group) and children vaccinated in a baby clinic or day-care centre were more likely to have received a valid schedule (OR: $2.3 ; 95 \%$ $\mathrm{Cl}:$ 1.8-5.1).

A survey conducted in Switzerland among physicians [30] showed that $93 \%$ of the 2,070 surveyed physicians agreed with current official vaccination recommendations and would apply them to their own children. As for MMR vaccine, however, more paediatricians had their children vaccinated with the vaccine according to the recommended schedule than the other physicians (OR: $2.8 ; 95 \% \mathrm{Cl}: 1.6-4.7$ ). A statistically significant number of non-paediatricians ( $4.8 \%$ ) did not have their own children vaccinated.

A total of 171 practitioners were interviewed in Denmark in a 1991 survey on their attitude with regard to the usefulness of MMR vaccination: all expressed a positive attitude, but only $56 \%$ of respondents expressed a wholeheartedly positive attitude. Average vaccination rates were connected with such attitudes, being $85 \%$ in practices with unreservedly positive attitudes and $69 \%$ in practices with more guarded attitudes [31].

\section{Providers of complementary}

medicine and homeopaths

Providers of complementary medicine are sometimes reported as having a negative attitude towards immunisation in general, including MMR [32]. Some studies have shown that homoeopathic physicians do not recommend or apply vaccinations as frequently as their allopathic colleagues [32-34].

A small study from Ernst et al. [33] in the UK $(n=23)$ on homeopaths' attitudes towards vaccination showed that all non-medically qualified homoeopaths refused vaccinations (13/13) but only 3 of the 10 medically qualified homoeopathic physicians did so.

In a 2002 UK study [34], Schmidt and Ernst evaluated and compared the response of professional homoeopaths, chiropractors and general practitioners to an inquiry about MMR vaccination. Of 104 homeopaths who responded to the survey, 40 advised explicitly against immunisation; another 26 withdrew their answer after being told that the query was, in fact, part of a research project. Out of 63 chiropractors, 3 advised against immunisation and 27 withdrew their answers.

Lehrke et al. [35] performed a study in 2001 among medically qualified homeopathic practitioners and non-homeopathic physicians (both generalists and paediatricians) in Germany about the administration and recommendation of 17 different vaccinations in their practices. The study showed that the responding homoeopathic physicians $(n=219)$ did not generally refuse vaccines but rather viewed them with a specific hierarchy: the 'classical' vaccines against tetanus, diphtheria and poliomyelitis were applied to nearly the same degree as by their non-homoeopathic colleagues $(n=281)$; however, vaccines against childhood diseases, including measles, were judged as ineffective and accepted with more restraint by homoeopathic physicians.

A 2001 French survey [28] involving 7,382 parents showed that coverage rates were significantly lower among children whose parents exclusively or sought advice from a homeopath (70\%), as compared with children whose parents never $(92.1 \%)$ or sometimes (90.1\%) did.

Impact of healthcare workers knowledge, attitudes and practice on parental vaccination choices for their children

Primary care providers have a central role in educating their patients on the safety and effectiveness of the MMR vaccine and can influence the rates of MMR immunisation just by answering parents' questions and addressing common misconceptions [36].

Several studies across Europe report that parents consider healthcare workers to be the most important source of information when deciding whether their children should be immunised with the MMR vaccine: $74 \%$ of mothers from a nationally representative sample of over 1,000 in a 2002 survey conducted in England reported seeking advice from health professionals before having their children immunised with the vaccine [37]. Information provided by healthcare workers was considered as the most influential and reliable by $77-78 \%$ of the respondents in a 2000 UK survey involving 300 mothers [38].

In a 2011 study [39] conducted in Sicily, one of the Italian regions with relatively high MMR vaccine coverage rates $(87 \%)$, the great majority of parents interviewed $(74 \%)$ singled out family paediatricians as the most important source of information. A total of $63 \%$ of mothers interviewed in a 2000 study [40] conducted in Italy also reported paediatricians to be their most important information source.

In Germany, 95\% of respondents considered their paediatrician as the most important source of information in a 2006 online survey [41]; doctors and nurses from Child Health Centres were trusted as the most important source by $77 \%$ of interviewed parents in Sweden in 2005 [42].

The first results from the European Vaccine Safety, Attitudes, Training and Communication (VACSATC) project of 2010 [43] - comparing five cross-sectional surveys of parents with children less than three years of age in England, Norway, Poland, Spain and Sweden $(6,611$ respondents) - showed that healthcare providers ranked first among most used and most trusted sources of information on vaccines. Health professionals were 
the most trusted by $92 \%$ of respondents in England; in Norway, the public health nurse was the most used source (49\%) and the public health doctor the most trusted (67\%); in Poland and Spain, the primary care physician was both the most used $(79 \%$ and $85 \%$, respectively) and most trusted ( $82 \%$ and $87 \%$, respectively) source; in Sweden the public health nurse was used as main source of information by $82 \%$ of respondents and was the most trusted by $87 \%$.

The attitude of the physician was mentioned as being very influential in the decision to vaccinate a child in the French-speaking community in Belgium [44].

In contrast, another survey conducted in the UK in 2007 showed a sharp drop in the level of trust in health professionals [45]. However, a 2010 systematic review by Brown et al. showed that parents are more likely to trust the information given to them by their general practitioners, health visitor or practice nurse than by the government: this relationship was observed in all five studies on the topic ( $p<0.05$ in three of the five) [46].

As seen in several studies, trust in individual health professionals and vaccine policymakers can be compromised by perceived conflicting interests (such as 'toeing the party line', meeting targets and giving financial compensation to doctors who reach high vaccine coverage rates) $[36,47]$. Health providers who were too resolute about the safety of the MMR vaccine led to parents questioning the providers' motives and knowledge; conversely, when the healthcare providers sounded vague, some parents interpreted this as concern that the vaccine was unsafe [47]. Such perceptions can be counteracted to some degree by trust in professional expertise and by healthcare workers sharing their personal experience (for example, confirming that they have vaccinated their own children) [36].

One of the most recurrently reported reasons for low vaccine acceptance rates is dissatisfaction with the adequacy of information provided to parents: a survey conducted in 2005 in the UK showed that $53 \%$ of respondents felt that doctors were too dismissive of parents' concerns about vaccine side effects. This figure rose to $89 \%$ among those who declined vaccination for their children [48].

A national survey conducted in Italy in 2003 showed that lack of appropriate information accounted for $22 \%$ of the missed or delayed MMR/measles vaccinations and intercurrent illness for $29 \%$ [49].

\section{Discussion}

Measles is a serious threat to public health: elimination of the disease in the EU is not only feasible, but necessary. Europe failed to meet the goal of eliminating measles by 2010 , because of lower-than-required vaccination coverage. The commitment has been renewed, to eliminate measles by 2015 [50]. However, instead of a progressive reduction of the disease in Europe, incidence and the number of outbreaks increased dramatically over the past 15 years, with unacceptable consequences in terms of mortality, morbidity and costs.

From our review, it is quite clear that doctors and other healthcare providers are regarded as the most reliable sources of information from parents. Healthcare workers are generally trusted and consulted on whether children should be vaccinated and they are in a good position to empower parents to take an informed decision about MMR vaccination for their children. If this is a reassuring thought, it has to be noted that trust towards healthcare workers on motives to vaccinate and safety and efficacy of the vaccine can be compromised if inadequate or vague information is provided or a conflict of interest perceived. For example, a history of safety issues cannot be denied but have to be explained in a clear and transparent manner. Parents need to be educated to make an informed choice.

Although a small percentage of practitioners, especially providers of complementary medicine, are against vaccines on principle, we found that the main problem among healthcare providers was lack of knowledge. In most cases, suboptimal vaccination rates resulted from inadequate knowledge among healthcare providers of vaccination schedules, as well as the benefits and side effects. In some cases, healthcare providers were even found to have misleading beliefs about immunisation and sent unclear or untrue messages to parents. Whenever healthcare workers' knowledge was found to be inadequate, vaccination coverage in the general population decreased. The same happened when healthcare workers were reported to have a relaxed attitude towards measles, which is itself a consequence of lack of knowledge of the disease infectivity and morbidity.

Even among providers of complementary medicine, medically qualified homeopaths tended to have a less negative attitude towards immunisation as compared with non-medically qualified practitioners [33].

A limitation of our study is related to the search strategy. Studies published in journals that are not indexed in MEDLINE and/or Embase (or cited in their references) were not included in the review: this might have caused us to overlook some evidence produced and published at a national level, especially in languages other than English. We know of at least one paper, published in the German Epidemiologisches Bulletin in 2008 [51], that was not included in the review for this reason, although the topic was relevant to our query. The authors surveyed attitudes and knowledge of childhood vaccination among 549 German midwives: about a quarter of the midwives interviewed did not support the administration of the MMR vaccine to children and over $40 \%$ considered diseases such as measles important for the personal development of the child. The survey also reported that over $10 \%$ of the sample 
disagreed with the statement 'measles infection can be fatal'. The survey showed a significantly lower support for MMR vaccination among midwives trained in alternative medicine $(p=0.025)$; furthermore, midwives who declared that they were against the administration of the vaccine were less likely to inform parents about the availability of the vaccine $(p=0.009)$.

Another potential limitation of this review is that all the studies considered were produced in western Europe (Table 2). This might warrant caution in the interpretation of the results. Attitudes and knowledge of immunisation among healthcare providers might not be the biggest problem in lower-resource countries, as in some Central and Eastern European countries, where low coverage rates might also be due to logistic and organisational issues in vaccine delivery. However, it should be noted that, with the exception of Romania (4,015 confirmed cases), the major outbreaks of measles in 2011 were reported in western European countries: France $(15,206$ confirmed cases), Italy $(5,181$ confirmed cases) and Spain (1,986 confirmed cases) [52]. For these countries, low vaccination coverage rates, and thus the high incidence of measles, are unarguably, at least in part, a consequence of a general complacency towards the disease and of loose strategies for vaccination coverage. This is partly due to false myths and anti-vaccine propaganda and partly to the fact that vaccination has made measles an uncommon disease, diluting perceptions and memories of how threatening it can be.

In order to improve vaccination coverage, therefore, it is fundamental to raise awareness about the disease and fill any knowledge gaps of healthcare workers, providing them with evidence-based information on vaccines and educating them to communicate effectively with patients and parents; this could be attained through dedicated websites and by emphasising vaccine education in the medical and nursing curricula. The Council of the European Union [53] has invited Member States to make efforts along these lines.

Similar to the situation for healthcare workers, we found that there was a small proportion of parents who were very reluctant to have their children vaccinated with the MMR vaccine, regardless of proof of its efficacy and safety. However, most vaccine-decliners are simply under-informed or received misconceived information $[24,28,36,37,43,48]$. Better informed and trained health professionals could have a substantial impact on the vaccination choices of those parents. For example, the results of Ciofi degli Atti et al. are indicative of the fact that that more efforts are needed to educate mothers (as well as physicians) regarding the risks associated with measles, as well as the fact that intercurrent illness is rarely a contraindication to immunisation [49].

Reaching $95 \%$ vaccine coverage is a priority for Europe. Measles was eliminated in 2002 in the Americas through universal coverage and active case surveillance [54].
One of the reasons behind this successful story in the Americas was good coordination among a consortium of countries. The Pan American Health Organization developed an enhanced and, most importantly, integrated disease elimination strategy [55].

The successful experience in the Americas shows the added value of addressing measles elimination at the European level. No country in Europe can attain it individually: only a joint effort will succeed.

\section{References}

1. World Health Organization (WHO). Measles fact sheet $\mathrm{N}^{\circ} 286$. Geneva: WHO; Apr 2012. Available from: http://www.who.int/ mediacentre/factsheets/fs286/en/index.html

2. Strebel PM, Papania MJ, Dayan GH, Halsey NA. Measles vaccines. In: Plotkin S, Orenstein W, Offit P. Vaccines. $5^{\text {th ed }}$ Saunders Elsevier; 2008. p. 353-98.

3. National Health Service (NHS). Complications of measles. [Accessed 23 Apr 2012]. Available from: http://www.nhs.uk/ Conditions/Measles/Pages/Complications.aspx

4. DrugsUpdate.com. Tresivac from Serum Institute [Vaccine, MMR]. [Accessed 23 April 2012]. Available from: http://www. drugsupdate.com/brand/generic/Vaccine,\%20MMR/4086

5. European Centre for Disease Prevention and Control (ECDC). Vaccination schedules. Stockholm: ECDC. [Accessed $23 \mathrm{Apr}$ 2012]. Available from: http://ecdc.europa.eu/en/activities/ surveillance/euvac/schedules/Pages/schedules.aspx

6. World Health Organization (WHO) Regional Office for Europe. Eliminating measles and rubella. Framework for the verification process in the WHO European Region. Copenhagen: WHO Regional Office for Europe; 2012. Available from: http://www. euro.who.int/_data/assets/pdf_file/0003/158304/EURO_MR_ Elimin_Verification_Processv2.pdf

7. Lopalco PL, Sprenger M. Do European doctors support measles, mumps, rubella vaccination programmes enough? Euro Surveill. 2011;16(39):pii=19979. Available from: http:// www.eurosurveillance.org/ViewArticle.aspx?Articleld=19979

8. Muscat M, Bang H, Wohlfahrt J, Glismann S, Mølbak K; EUVAC. NET Group. Measles in Europe: an epidemiological assessment. Lancet. 2009;373(9661):383-9.

9. European Centre for Disease Prevention and Control (ECDC). European monthly measles monitoring (EMMO). September 2011. Stockholm: ECDC; 2011. Available from: http://www. ecdc.europa.eu/en/publications/Publications/111018_EMMO_ SEPT_2011.pdf

10. van Esso D, del Torso S, Hadjipanais A, Biver A, Jaeger-Roman $E$, Wettergren B, et al. Paediatric primary care in Europe: variation between countries. Arch Dis Child. 2010;95(10):791-5.

11. VENICE Working Group. Report on first Survey of immunisation programs in Europe. VENICE; 2007. Available from: http:// venice.cineca.org/Report_II_WP3.pdf

12. National Institutes of Health (NIH). Measles database. Bethesda, MD: NIH. [Accessed 23 April 2012]. Available from: http://science.education.nih.gov/supplements/nih1/diseases/ activities/activity5 measles-database3.htm

13. Wakefield AJ, Murch SH, Anthony A, Linnell J, Casson DM, Malik $M$, et al. Ileal-lymphoid-nodular hyperplasia, non-specific colitis, and pervasive developmental disorder in children. Lancet. 1998;351(9103):637-41.

14. Retraction - Ileal-lymphoid-nodular hyperplasia, non-specific colitis, and pervasive developmental disorder in children. Lancet. 2010;375(9713):445. Retraction of: Wakefield AJ, Murch SH, Anthony A, Linnell J, Casson DM, Malik M, et al. Lancet. 1998;351(9103):637-41.

15. American Academy of Pediatrics (AAP). Facts for parents about vaccine safety. Elk Grove Village, IL: American Academy of Pediatrics; March 2008. Press release. Available from: http:// www2.aap.org/advocacy/releases/autismfactsforparents.pdf

16. Taylor B, Miller E, Farrington CP, Petropoulos MC, FavotMayaud I, Li J, et al. Autism and measles, mumps, and rubella vaccine: no epidemiological evidence for a causal association. Lancet. 1999;353(9169):2026-9. 
17. Kaye JA, del Mar Melero-Montes M, Jick H. Mumps, measles, and rubella vaccine and the incidence of autism recorded by general practitioners a time-trend analysis. West J Med. 2001;174(6):387-90.

18. Return of the measles parties (or why parents fear MMR jabs) Daily Mail. 15 Feb 2000. Available from: http://www.whale.to/ vaccines/measles7.html

19. Simpson N, Lenton S, Randall R. Parental refusal to have children immunised: extent and reasons. BMJ. 1995;310(6974):227.

20. Burton-Jeangros C, Golay M, Sudre P. [Compliance and resistance to child vaccination: a study among Swiss mothers]. Rev Epidemiol Sante Publique. 2005;53(4):341-50. French.

21. Anastasi D, Di Giuseppe G, Marinelli P, Angelillo IF. Paediatricians knowledge, attitudes, and practices regarding immunizations for infants in Italy. BMC Public Health. 2009;9:463.

22. Angelillo IF, Ricciardi G, Rossi P, Pantisano P, Langiano E, Pavia M. Mothers and vaccination: knowledge, attitudes, and behaviour in Italy. Bull World Health Organ. 1999;77(3):224-9.

23. Commité français d'éducation pour la santé. Vaccination rougeole, oreillons, rubéole. Des inégalités persistantes. [French health education committee. Measles, mumps and rubella vaccination : persisting inequalities]. Commité français d'éducation pour la santé; Sep 2001. Dossier de presse. Available from: http://www.inpes.sante.fr/70000/dp/01/ dp010907.pdf

24. Hak E, Schönbeck Y, De Melker H, Van Essen GA, Sanders EA. Negative attitude of highly educated parents and health care workers towards future vaccinations in the Dutch childhood vaccination program. Vaccine. 2005;23(24):3103-7.

25. Petrovic M, Roberts R, Ramsay M. Second dose of measles, mumps, and rubella vaccine: questionnaire survey of health professionals. BMJ. 2001;322(7278):82-5.

26. Smith A, McCann R, McKinlay I. Second dose of MMR vaccine: health professionals' level of confidence in the vaccine and attitudes towards the second dose. Commun Dis Public Health. 2001;4(4):273-7.

27. Cotter S, Ryan F, Hegarty H, McCabe TJ, Keane E. Immunisation: the views of parents and health professionals in Ireland. Euro Surveill. 2003;8(6):pii=416. Available from: http://www. eurosurveillance.org/ViewArticle.aspx?Articleld=416

28. Rotily M, Guagliardo V, Fontaine D, Garros B, Mayer C, Arrighi J, et al. [Evaluation of measles, mumps and rubella vaccine coverage in 3 year old children in twelve French counties. Time-trends and related factors. Rev Epidemiol Sante Publique. 2001;49(4):331-41. French.

29. Theeten H, Hens N, Vandermeulen C, Depoorter AM, Roelants $M$, Aerts $M$, et al. Infant vaccination coverage in 2005 and predictive factors for complete or valid vaccination in Flanders, Belgium: an EPI-survey. Vaccine. 2007;25(26):4940-8.

30. Posfay-Barbe KM, Heininger U, Aebi C, Desgrandchamps $D$, Vaudaux B, Siegrist CA. How do physicians immunize their own children? Differences among pediatricians and nonpediatricians. Pediatrics. 2005;116(5);e623-33.

31. Trier H. Doctors' attitudes and MMR-vaccination. Scand J Prim Health Care. 1991;9(1):29-33.

32. Ernst $E$. The attitude against immunisation within some branches of complementary medicine. Eur J Pediatr. 1997;156(7):513-5.

33. Ernst E, White AR. Homoeopathy and immunization. Br J Gen Pract. 1995;45(400):629-30.

34. Schmidt K, Ernst E. Aspects of MMR. Survey shows that some homoeopaths and chiropractors advise against MMR. BMJ. 2002;325(7364):597.

35. Lehrke P, Nuebling M, Hofmann F, Stoessel U. Attitudes of homoeopathic physicians towards vaccination. Vaccine. 2001;19(32):4859-64.

36. Mc Murray R, Cheater FM, Weighall A, Nelson C, Schweiger $M$, Mukherjee S. Managing controversy through consultation: a qualitative study of communication and trust around MMR vaccination decisions. Br J Gen Pract. 2004;54(504):520-5.

37. Ramsay ME, Yarwood J, Lewis D, Campbell H, White JM. Parental confidence in measles, mumps and rubella vaccine: evidence from vaccine coverage and attitudinal surveys. $\mathrm{Br}$ J Gen Pract. 2002;52(484):912-6.

38. Pareek M, Pattison HM. The two-dose measles, mumps, and rubella (MMR) immunisation schedule: factors affecting maternal intention to vaccinate. Br J Gen Pract, 2000;50(461):969-71.

39. Coniglio MA, Platania M, Privitera D, Giammanco G, Pignato S. Parents' attitudes and behaviours towards recommended vaccinations in Sicily, Italy. BMC Public Health. 2011;11:305.
40. Impicciatore $\mathrm{P}$, Bosetti C, Schiavio S, Pandolfini C, Bonati M. Mothers as active partners in the prevention of childhood diseases: maternal factors related to immunization status of preschool children in Italy. Prev Med. 2000l;31(1):49-55.

41. Heininger U. An internet-based survey on parental attitudes towards immunization. Vaccine. 2006;24(37-39):6351-5.

42. Dannetun E, Tegnell A, Hermansson G, Giesecke J. Parents' reported reasons for avoiding $M M R$ vaccination. A telephone survey. Scand J Prim Health Care. 2005;23(3):149-53.

43. Stefanoff P, Mamelund SE, Robinson M, Netterlid E, Tuells J Bergsaker MA, et al. Tracking parental attitudes on vaccination across European countries: The Vaccine Safety, Attitudes, Training and Communication Project (VACSATC). Vaccine. 2010;28(35):5731-7.

44. Swennen B, Van Damme P, Vellinga A, Coppieters $Y$, Depoorter AM. Analysis of factors influencing vaccine uptake: perspectives from Belgium. Vaccine. 2001;20 Suppl 1:S5-7; discussion $\mathrm{S}_{1}$

45. Smith A, Yarwood J, Salisbury DM. Tracking mothers' attitudes to MMR immunisation 1996-2006. Vaccine. 2007;25(20):3996-4002.

46. Brown KF, Kroll JS, Hudson MJ, Ramsay M, Green J, Long SJ, et al. Factors underlying parental decisions about combination childhood vaccinations including MMR: a systematic review. Vaccine. 2010;28(26):4235-48.

47. Hilton S, Petticrew M, Hunt K. Parents' champions vs. vested interests: who do parents believe about MMR? A qualitative study. BMC Public Health. 2007;7:42.

48. Casiday R, Cresswell T, Wilson D, Panter-Brick C. A survey of UK parental attitudes to the MMR vaccine and trust in medical authority. Vaccine. 2006;24(2):177-84.

49. Ciofi degli Atti ML, Rota MC, Bella A, Salmaso S; ICONA Study Group. Do changes in policy affect vaccine coverage levels? Results of a national study to evaluate childhood vaccination coverage and reasons for missed vaccination in Italy. Vaccine. 2004;22(31-32):4351-7.

50. World Health Organization (WHO) Regional Office for Europe. Resolution. Renewed commitment to elimination of measles and rubella and prevention of congenital rubella syndrome by 2015 and Sustained support for polio-free status in the WHO European Region. Regional Committee for Europe Sixtieth session. Moscow, 13-16 September 2010. Copenhagen: WHO Regional Office for Europe; 16 Sep 2010. Available from: http:// www.euro.who.int/_data/assets/pdf_file/0016/122236/ RC60_eRes12.pdf

51. Impfstatus sowie Einstellung und Verhalten von Hebammen zu Impfungen - Ergebnisse einer Querschnittsstudie. [Vaccination status, Perception and Attitude of midwifes towards vaccination - results of a cross sectional study]. Epidemiologisches Bulletin. 2008;21:163-72. German. Available from: http://edoc.rki.de/documents/rki_fv/reYq8gLvybNOo/ PDF/24iEyYcdYnnL2Y.pdf

52. European Centre for Disease Prevention and Control (ECDC). European monthly measles monitoring (EMMO). Issue 8: 21 February 2012. Stockholm: ECDC; 2012. Available from: http:// ecdc.europa.eu/en/publications/Publications/SUR EMMO European-monthly-measles-monitoring-February-2012.pdf

53. Council of the European Union. Council conclusions on childhood immunisation: successes and challenges of European childhood immunisation and the way forward. Luxembourg: Council of the European Union; 6 Jun 2011. Available from: http://www.consilium.europa.eu/uedocs/ cms_Data/docs/pressdata/en/lsa/122391.pdf

54. Centers for Disease Control and Prevention (CDC). Progress toward elimination of measles from the Americas. MMWR Morb Mortal Wkly Rep. 1998;47(10):189-92. Available from: http:// ftp.cdc.gov/pub/Publications/mmwr/wk/mm4710.pdf

55. de Quadros CA, Hersh BS, Nogueira AC, Carrasco PA, da Silveira CM. Measles eradication: experience in the Americas. MMWR Morb Mortal Wkly Rep. Supplement. 1999;48(SU01):5764. Available from: http://www.cdc.gov/mmwr/preview/ mmwrhtml/su48a12.htm 